\title{
Abdominal Injury Caused by an Air Gun Shot
}

\section{Pil Young Jung, Hongjin Shim}

Department of Surgery, Yonsei university Wonju college of medicine, Wonju Severance Christian Hospital, Trauma center

Gunshot injury is uncommon in South Korea. Here, we present a case of penetrating abdominal injury caused by an air gun shot.

Key Words: Abdomen; Wounds, Gunshot

(Trauma Image Proced 2018(1):8-10)

\section{CASE}

A 54-year-old male with no medical history was admitted to the emergency room with penetrating abdominal injury caused by an accidental air gun shot. Upon admission, he was hemodynamically stable and showed one entrance wound site on his abdomen (Fig. 1.). His plain X-ray and CT (Fig. 2.) revealed a bullet located in the abdomen wall. Accordingly, we planned an emergency surgery and detected omental injury, perforation of the anterior and posterior walls of the stomach, and multiple perforations of the ileum (at 5 sites) (Fig. 3.). We then performed primary repair of the stomach and ileum and removed the bullet. The patient recovered without any complications.

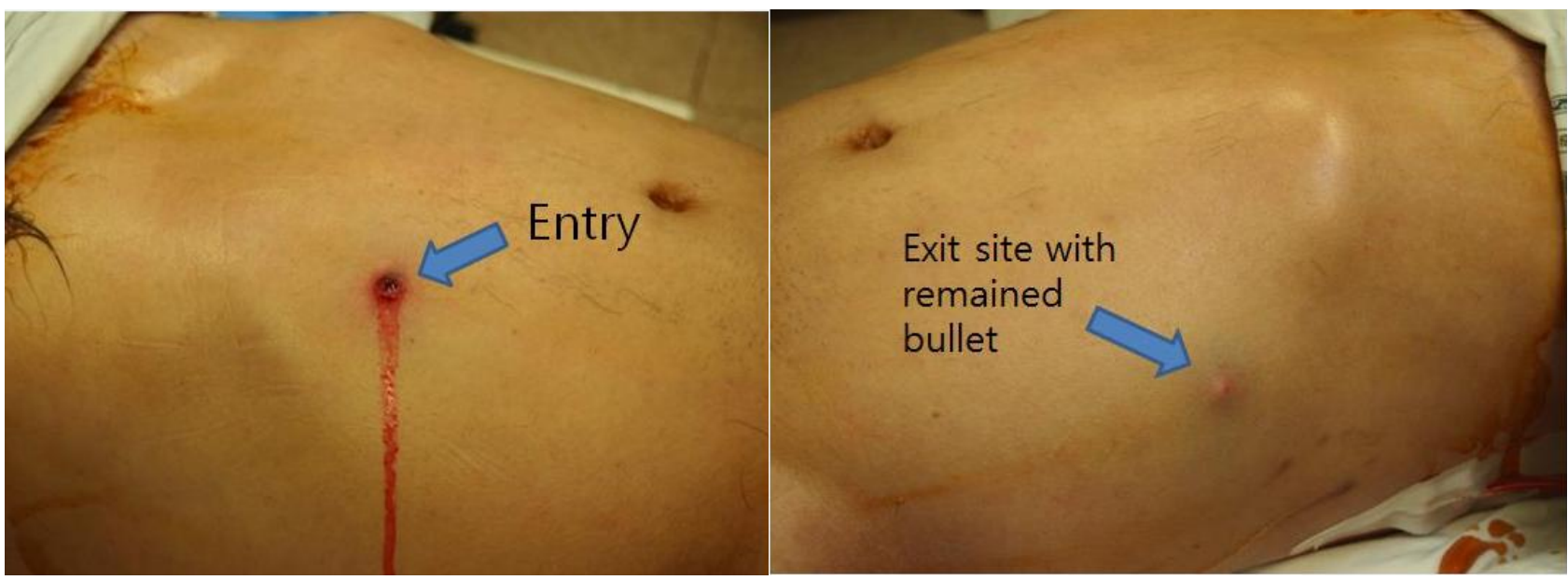

Fig. 1. One entry and exit site, with remaining bullets on the abdomen

Received: April 25, 2018 Revised: May 16, 2018 Accepted: May 17, 2018

Correspondence to: Pil Young Jung, Department of Surgery, Yonsei university Wonju college of medicine, Wonju Severance Christian Hospital, 220-701, 20 IIsan-ro, Wonju-si, Gangwon-do, South Korea

Tel: 82-33-741-0882, Fax: 82-33-741-0574, E-mail: surgery4trauma@yonsei.ac.kr

Copyright (c) 2018 Korean Association for Research, Procedures and Education on Trauma. All rights reserved.

(c) This is an open-access article distributed under the terms of the Creative Commons Attribution Non-Commercial License (http://creativecommons.org/ licenses/by-nc/4.0) which permits unrestricted noncommercial use, distribution, and reproduction in any medium, provided the original work is properly cited 

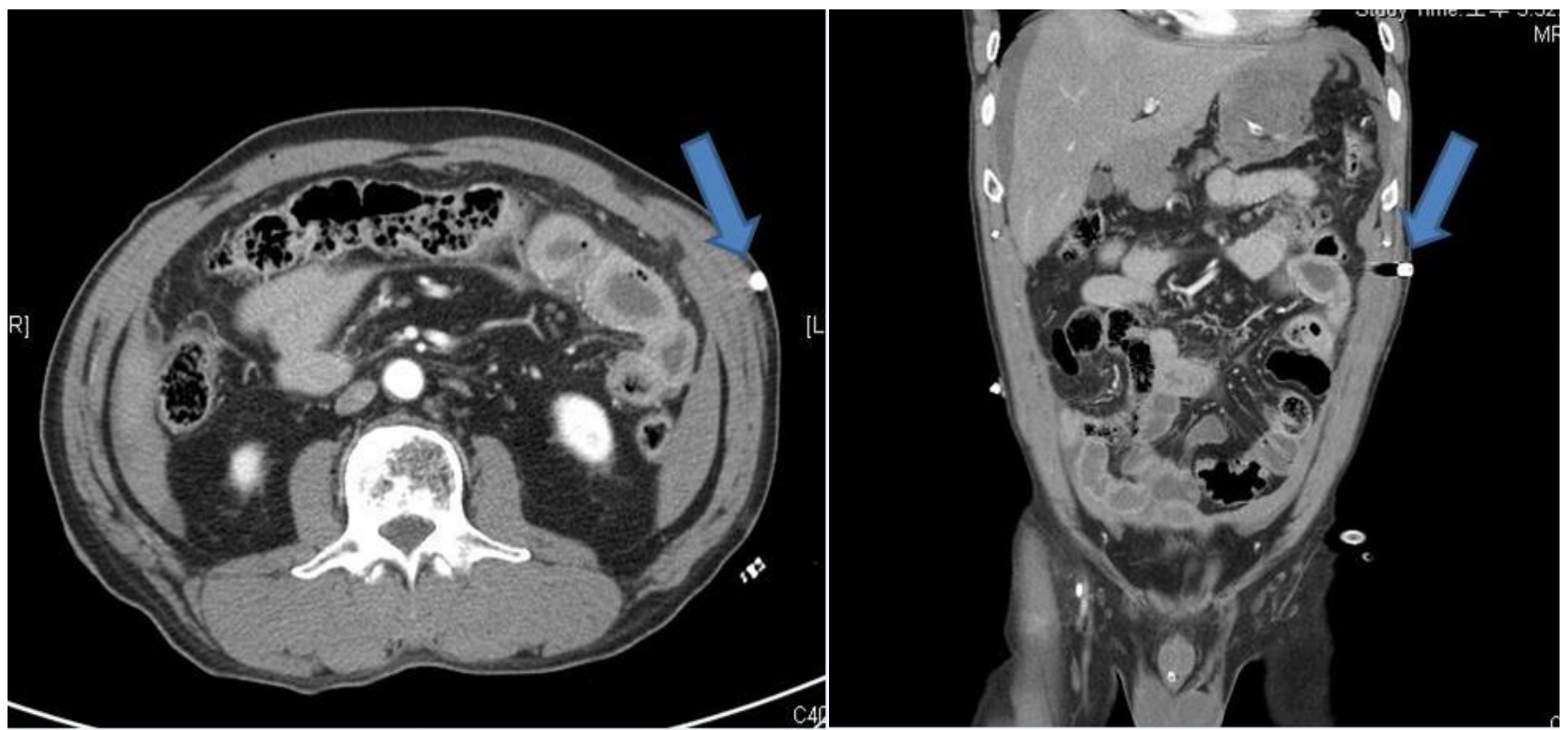

Fig. 2. CT scan revealing the bullet lodged in the abdominal wall

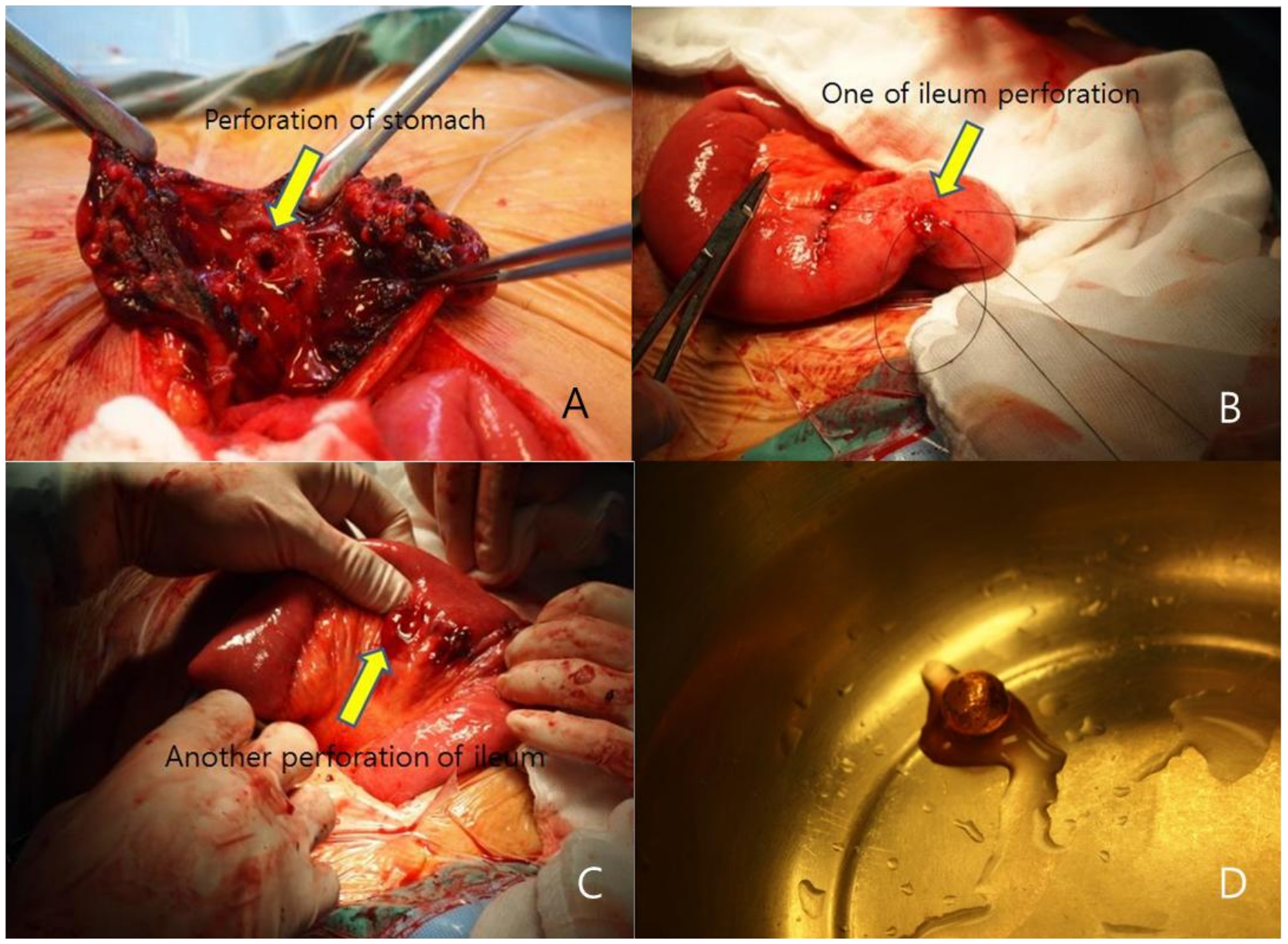

Fig. 3. $(A, B, C)$ The surgical finding of the stomach and ileum and (D) removed bullet 


\section{DISCUSSION}

The gunshot injury wound depends on the characteristics of bullet yawing, position, and section of the wound ballistics or profile (1). Gunshot injury from a bullet traveling at a speed of $<1100 \mathrm{ft} / \mathrm{s}$ is considered a low-velocity injury, such as with an air gun. Conventionally, the standard choice of treatment for gunshot wounds in the abdomen has been laparotomy (2). Lee et al. reported several combat-related gunshot injury cases in South Korea; however, gunshot injury cases are relatively rare in South Korea (3). Despite of this, we need to be prepared for proper management of such cases in the future.

\section{Conflict of Interest Statement}

No potential conflict of interest relevant to this article was reported.

\section{REFERENCES}

1. Peonim V, Srisont S, Udnoon J, et al. Entrance and exit wounds of high velocity bullet: An autopsy analysis in the event of dispersing the mass rally in Bangkok Thailand, May 2010. Leg Med (Tokyo) 2016 Nov; 23: 10-16

2. Singh N, Hardcastle TC Selective non operative management of gunshot wounds to the abdomen: a collective review. Int Emerg Nurs. 2015 Jan; 23(1):22-31

3. JE Lee, YH Lee, GH Baek, et al. Treatment of Combat-realated Gunshot and Explosive Injuries to the Extremities. J Korean Soc Traumatol 2013; 26(3): 111-124 